\title{
High mating success of low rank males in Limia perugiae (Pisces: Poeciliidae) as determined by DNA fingerprinting
}

\author{
M. Schartl ${ }^{\mathrm{a}}$, C. Erbelding-Denk ${ }^{\mathrm{b}}, \mathrm{S}$. Hölter ${ }^{\mathrm{a}}$, I. Nanda ${ }^{\mathrm{c}}, \mathrm{M}$. Schmid ${ }^{\mathrm{c}}$, \\ J. H. Schröder ${ }^{b}$ and J. T. Epplen ${ }^{d}$ \\ ${ }^{a}$ Physiologische Chemie I, Theodor-Boveri-Institut für Biowissenschaften am Biozentrum der \\ Universität, Am Hubland, 97074 Würzburg, Germany; ${ }^{\mathrm{b}}$ Institut für Säugetiergenetik, GSF \\ Forschungszentrum, Ingolstädter Landstraße 1, 85764 Neuherberg, Germany; 'Institut für \\ Humangenetik am Biozentrum der Universität, Am Hubland, 97074 Würzburg, Germany; \\ and ${ }^{\mathrm{d}}$ Molekulare Humangenetik, Ruhr-Universität, 44780 Bochum, Germany
}

\begin{abstract}
Summary
Hierarchical structures among male individuals in a population are frequently reflected in differences in aggressive and reproductive behaviour and access to the females. In general social dominance requires large investments which in turn may have to be compensated for by high reproductive success. However, this hypothesis has so far only been sufficiently tested in small mating groups due to the difficulties of determining paternity by classical methods using non-molecular markers. DNA fingerprinting overcomes these problems offering the possibility to determine genetic relationships and mating patterns within larger groups. Using this approach we have recently shown (Schartl et al., 1993) that in the poeciliid fish Limia perugiae in small mating groups the dominant male has $100 \%$ mating success, while in larger groups its contribution to the offspring unexpectedly drops to zero. The reproductive failure under such social conditions is explained by the inability of the $\alpha$-male to protect all the females simultaneously against mating attempts of his numerous subordinate competitors.
\end{abstract}

\section{Introduction}

In many species of poeciliids males are polymorphic for body size (Constantz, 1975; Kallman, 1984; Hughes, 1985). Large males outcompete smaller ones and become dominant in the social structure of a given group (see Farr, 1989). In at least one genus it has been conclusively shown that differences in body size result primarily from allelic variation of a single polymorphic Y chromosome linked locus (known as the $P$-locus, Kallman and Schreibman, 1973; Kallman, 1984; Borowsky, 1987; Kallman, 1989). The different size classes differ with respect to their sexual behaviour. Large males display a pronounced courtship behaviour that precedes copulation attempts while small males show simple "sneaking" behaviour (Constantz, 1975; Ryan, 1988; Zimmerer and Kallman, 1989). This is in agreement with considerations 
that in the natural environment alternate mating tactics exist as an evolutionarily stable strategy (Maynard Smith, 1976, 1981). Large males reach sexual maturity at a much later age than smaller ones imposing costs in form of an increased risk of pre-reproductive mortality (Hughes, 1985) due to predation, etc. Additional costs of a courting male include a higher risk of becoming predated because of its garishness due to the more brilliant coloration of the $\alpha$-animal (Farr, 1975; Endler, 1980) and the energy input required to defend the hierarchy and protect females from the mating attempts of subordinate males. In female choice tests large males are preferred (Ryan and Wagner, 1987; Zimmerer and Kallman, 1989; Hughes, 1985). The large, spectacularly pigmented male morphs are the result of sexual selection. Behavioural polymorphisms as well as the accompanying phenotypic polymorphisms are maintained or balanced by natural selection.

Using phenotypic markers in progeny tests of two females with one large and one small male the dominant large male was found to be rewarded by a greater reproductive success (Zimmerer and Kallman, 1989). In the guppy dominant males were more successful even when the females showed preference for the subordinate male (Kodric-Brown, 1992). All these observations are in agreement with the expected increased fitness for the $\alpha$-animal.

We have used Limia perugiae, a poeciliid fish endemic to the southeast of the Caribbean island Hispaniola, to study mating patterns in relation to male polymorphism and mating group size by DNA fingerprinting. These fish inhabit freshwater biotopes, clear springs as well as muddy creeks and polluted man-made ditches. Males are polymorphic for adult size ranging from 20 up to sometimes $60 \mathrm{~mm}$ total length. The onset of sexual maturation which results in cessation of growth is determined by a genetic system comparable to the $P$-locus of Xiphophorus with Y-chromosomal alleles for large and small size. However, additionally at least one autosomal modifier locus interacts with $P$, thus allowing intermediate size males to appear (Erbelding-Denk et al., submitted). Of course environmental factors modulate to a certain extent the final size of each genotype. Females constitute a single size class with a mean adult size of $40 \mathrm{~mm}$. Like all other poeciliid fish species they are livebearing and do not provide parental care. Males are not territorial. The sex ratio is on average one to one. The highest rank males are marked by a very intensive coloration: blue body contrasted by a black dorsal fin and a bright yellow caudal fin with black margin.

Simple repeat oligonucleotides are useful tools to study genetic relationships within all species tested at all levels of eukaryotic organismic evolution (Epplen et al., 1991). This approach seemed especially advantageous to determine paternity in large social groups (Burke, 1989). 


\section{Materials and methods}

For details on the experimental animals see Schartl et al. (1993). DNA was prepared from pooled organs of individual fish and processed for restriction enzyme digest and agarose gel electrophoresis essentially as described (see Schartl, 1988). For DNA fingerprinting the gel was dried and hybridized to ${ }^{32} \mathrm{P}$-end labelled oligonucleotides. For details on the hybridization and washing conditions see Nanda et al. (1990). Paternity was determined after 3-4 oligonucleotide hybridization steps by comparing all multilocus fingerprint patterns of each child with those of the mother defining the paternally inherited bands. The latter were compared to the patterns of the putative fathers thus sequentially excluding each of the non-fathers.

\section{Results}

In a first series of mating experiments one large and one small male were tested with two females. Offspring from two different broods in two independent experiments were analysed for paternity. In the first experiment 13 of 14 animals were attributable to the large dominant male and one was of uncertain paternity. In the second case all $12 \mathrm{~F}_{1}$ fish tested were unequivocally offspring of the $\alpha$-male. These observations are in accordance with findings using similar sized mating groups in the pygmy swordtail, Xiphophorus nigrensis (Zimmerer and Kallmann, 1989) and the guppy, Poecilia reticulata (Kodric-Brown, 1992). The reproductive success of the large male in this kind of competition experiment can be attributed to the selective advantage gained by its dominance and the pronounced courtship behaviour. It is in perfect agreement with the expectation that a high commitment of energy and cost into sexual and social behaviour leads to high fitness. If the aforementioned test situation relates to anything determining the evolutionary history of $L$. perugiae in feral populations, this, however, would predict that the small phenotype which is invariably connected to subordinateness is prone to disappearance by negative selection.

In the second set of experiments four males ranging in size from $25 \mathrm{~mm}$ to $49 \mathrm{~mm}$ were assembled with four or five juvenile, virgin females. Within few days the male fish established size-dependent ranking that remained stable throughout the duration of the experiment. Neonates were taken out of the aquarium immediately after birth and raised separately. DNA fingerprinting of a representative number of offspring $(n=155)$ revealed that most females had contributed to the offspring generation and that generally individual broods were of mixed paternity. After experiments 2 and 3 full fertility of the $\alpha$ males was confirmed by mating them without competition to virgin females. 


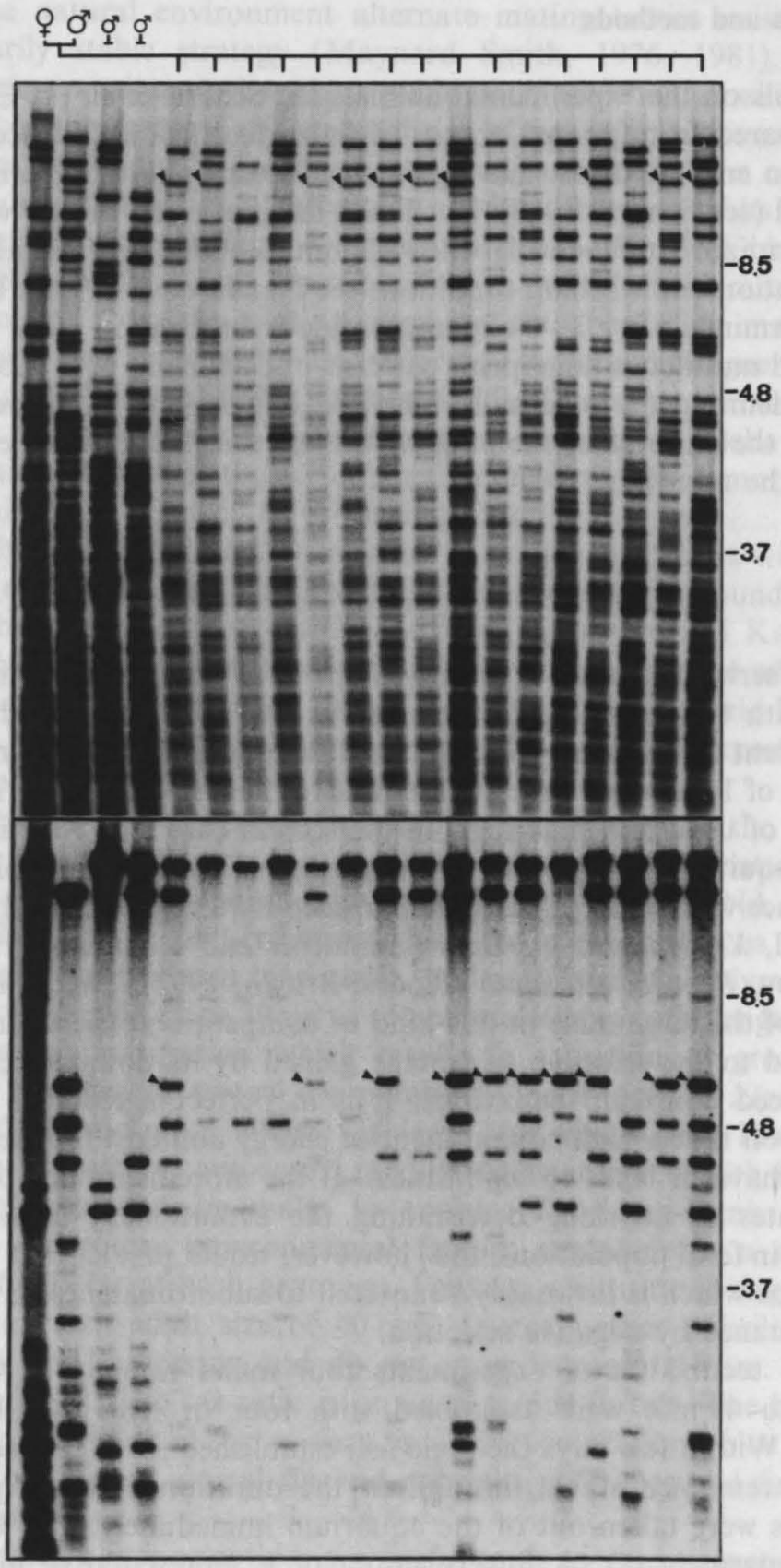

Figure 1. Determination of paternity in large mating groups of $L$. perugiae by DNA fingerprinting showing three possible fathers ( $\delta$; lanes $2-4$ from left: $\beta-, \gamma$ - and $\omega$-males), the mother ( $\left(\right.$; lane 1) as well as their offspring as obtained with the probes (GGAT) ${ }_{4}$ (top) and $(\mathrm{CA})_{8}$ (bottom). Representative diagnostic bands could only be transmitted by one of the possible fathers (arrows). Fragment length markers are indicated in kilobase pairs on the right. 
In the first mating group all offspring tested were from the subordinate $\beta$-male (see Fig. 1). In the second and third group paternity was assigned to the $\beta$ and $\gamma$ males. In all cases the smallest and most subordinate male never had offspring. This is in agreement with its exclusively defensive behaviour. Surprisingly, we could not identify progeny of the dominant male (see Tab. 1). This observation is in direct contradiction to the expected results and the behavioural data on fish reported so far. However, the only component of fitness that has been possible to monitor before is the number of observed matings or mating attempts by each male, but even this may be misleading as the number of successful fertilizations can be substantially different. After analysing the genetic relationships of the progeny with the males it became apparent that intermediate size males, that exhibit only little courtship but simple "sneaking" behaviour are more effective reproductively than the more extreme social and size classes (represented by the $\alpha$ and $\omega$ males), who are practically excluded from reproduction. The size of the group used in the second set of experiments is more similar to the situation found in nature (Lechner and Radda, 1980; Lechner and Meyer, pers. commun.) and may help to explain the result obtained. As population size increases the dominant male must spend more time fighting and less time pursuing females. Futhermore, attacks on non-aggressive subordinates decrease as aggressive males devote proportionally more time fighting each other allowing lower rank males a greater opportunity to successfully mate. To test this hypothesis the behaviour of the males was quantified (according to Parzefall, 1969). It was revealed that indeed the dominant male spent most of his time with agonistic behaviour and also courtship display (Schartl et al., 1993). Under such social conditions the highest rank male is heavily engaged in defending the hierarchy and protecting females from mating attempts of his competitors. As he spends a lot of time with courtship display, the dominant male is obviously not able

Table 1. Paternity of offspring in large mating groups of Limia perugiae

\begin{tabular}{lrrrll}
\hline Trial & $x$ & $\beta$ & $\gamma$ & $\omega$ & uncertain \\
\hline I & 0 & 29 & 0 & 0 & $1^{*}$ \\
II & 0 & 53 & 15 & 0 & $8^{* *}$ \\
III & 0 & 24 & 12 & 0 & $3^{* *}$ \\
IV & 12 & 8 & 7 & 5 & 0 \\
\hline
\end{tabular}

*not unequivocally ascribable to one of the four possible fathers because of too few paternal bands transmitted. **attributable either to $\beta$ or $\gamma$. "social hierarchy less clearly established, see text. 
to prevent the subordinates from successful mating after simple "sneaking" behaviour.

In a fourth independent large mating group males were assembled that did not establish a pronounced hierarchy although size differences allowed some ranking. The lowest rank male did not exhibit hiding, and the $\alpha$-male was far less aggressive than in the three other mating groups. In this experiment all four males produced offspring.

\section{Discussion}

The question arises as to how in the mating system identified for larger social groups with a pronounced hierarchy a size polymorphism in males can be maintained if the genes of the extreme size class males are only rarely transmitted to the progeny. If size is determined by polygenic systems and/or environmental conditions the maintenance of polymorphisms is readily explained. However, if a single locus, such as the $P$-locus of Xiphophorus (Kallman, 1984), is of major importance in determining the onset of maturation and therefore adult size, only a balanced system of different modifier alleles for $P$ present in males and females will guarantee the reappearance of all size classes in the offspring generations.

Our findings in $L$. perugiae are not compatible with the current understanding that social dominance increases reproductive success. We cannot exclude that the mating system that we observed in $L$. perugiae will be unstable in the long run. A possible explanation for the observed phenomenon, however, would be "inclusive fitness" (Hamilton, 1964). Populations of $L$. perugiae like most poeciliid fish live in limited habitats. Therefore the chance that a subordinate male is a close relative to the dominant male is high. It should also be taken into consideration that $L$. perugiae like most teleosts produce a large surplus of offspring of which only a minute number reaches maturity due to heavy predative pressure. This may counteract or bias the gene pool of the survivors as compared to the newborn population. In any of the possible explanations the biological significance of aggressiveness, social hierarchy and courtship behaviour remains obscure.

The difference observed in reproductive success of the dominant $L$. perugiae male in small and large groups documents the need to apply efficient molecular biology methods to study also in other species mating success in groups larger than the 3-4 individuals that can be studied by conventional methods. DNA fingerprinting provides the powerful tool to extend such analyses even to the genetic relationships in natural populations. Such data will provide the most relevant basis for sociobiological considerations. 


\section{Acknowledgements}

We thank B. Wilde for technical assistance and M. Meyer (Bad Nauheim) for helpful information on the biology of L. perugiae in its natural habitats and for supplying founder fish for our stocks. Supported by grants to Ma. S. (DFG), J. T. E. (VW-Stiftung) and Mi. S. (DFG).

\section{References}

Borowsky RL (1987) Genetic polymorphism in adult male size in Xiphophorus variatus (Atheriniformes: Poeciliidae). Copeia 1987: 782-787

Burke T (1989) DNA fingerprinting and other methods for the study of mating success. Trends Ecol Evol 4: 139-144

Constantz GD (1975) Behavioural ecology of mating in the male Gila topminnow, Poeciliopsis occidentalis (Cypridontiformes: Poeciliidae). Ecology 36: 966-973

Endler JA (1980) Natural selection on color patterns in Poecilia reticulata. Evolution 34: $76-91$

Epplen JT, Ammer H, Epplen C, Kammerbauer C, Mitreiter R, Roewer L, Schwaiger W et al. (1991) Oligonucleotide fingerprinting using simple repeat motifs: a convenient, ubiquitously applicable method to detect hypervariability for multiple purposes. In: Burke T, Dolf G, Jeffreys AJ, Wolff R (eds) DNA Fingerprinting: Approaches and Applications. Birkhäuser Verlag, Basel, pp 50-69

Erbelding-Denk C, Schröder JH, Schartl M, Nanda I, Schmid M, Epplen JT. Male polymorphism in Limia perugiae (Pisces: Poeciliidae) (submitted)

Farr JA (1975) The role of predation in the evolution of social behavior of natural populations of the Guppy, Poecilia reticulata (Pisces: poeciliidae). Evolution 29: $151-158$

Farr JA (1989) Sexual selection and secondary sexual differentiation in Poeciliids: determinants of male mating success and the evolution of female choice. In: Meffe GK, Snelson FF $\mathrm{Jr}$ (eds) Ecology and Evolution of Livebearing Fishes (Poeciliidae). Prentice Hall, Englewoods Cliffs, New Jersey, pp 91-123

Hamilton WD (1964) The genetical evolution of social behaviour. J Theor Biol 7: 1-16

Hughes AL (1985) Male size, mating success, and mating strategy in the mosquitofish Gambusia affinis (Poeciliidae). Behav Ecol Sociobiol 17: 271-278

Kallman KD (1984) A new look at sex determination in Poeciliid Fishes. In: Turner BJ (ed) Evolutionary Genetics of Fishes. Virginia Polytechnic Institute and State University, Blacksburg, Virginia. Plenum Press, New York, pp 95-171

Kallman KD (1989) Genetic control of size at maturity in Xiphophorus. In: Meffe GK, Snelson FF Jr (eds) Ecology and Evolution of Livebearing Fishes (Poeciliidae). Prentice Hall, Englewood Cliffs, New Jeresy, pp 163-184

Kallman KD, Schreibman MP (1973) A sex-linked gene controlling gonadotrop differentiation and its significance in determining the age of sexual maturation and size of the platyfish, Xiphophorus maculatus. Gen Comp Endocrinol 21: 287-304

Kodric-Brown A (1992) Male dominance can enhance mating success in guppies. Anim Behav 44: $165-167$

Lechner P, Radda AC (1980) Poeciliiden-Studien in der Dominikanischen Republik. Aquaria 27: $1-13$

Maynard Smith J (1976) Evolution and the theory of games. Amer Sci 64: 41-45

Maynard Smith J (1981) Will a sexual population evolve to an ESS? Amer Natur 117: 1015-1018

Nanda I, Feichtinger W, Schmid M, Schröder JH, Zischler H, Epplen JT (1990) Simple repetitive sequences are associated with differentiation of the sex chromosomes in the Guppy fish. J Mol Evol 30: 456-462

Parzefall J (1969) Zur vergleichenden Ethologie verschiedener Mollienesia Arten einschlieBlich einer Höhlenform von $M$. sphenops. Behaviour 33: 1-37

Ryan MJ (1988) Phenotype, genotype, swimming endurance and sexual selection in a swordtail (Xiphophorus nigrensis). Copeia 1988: 484-487 
Ryan MJ, Wagner WE (1987) Asymmetries in mating preferences between species: Female swordtails prefer heterospecific males. Science 236: 595-597

Schartl M (1988) A sex chromosomal restriction-fragment-length marker linked to melanomadetermining $T u$ loci in Xiphophorus. Genetics 119: 679-685

Schartl M, Erbelding-Denk C, Hölter S, Nanda I, Schmid M, Schröder JH, Epplen JT (1993) Reproductive failure of dominant males in the poeciliid fish Limia perugiae determined by DNA-fingerprinting. Proc Natl Acad Sci USA (in press)

Zimmerer EJ, Kallman KD (1989) Genetic basis for alternative reproductive tactics in the pygmy swordtail, Xiphophorus nigrensis. Evolution 43: 1298-1307 